\title{
A novel praziquantel solid lipid nanoparticle formulation shows enhanced bioavailability and antischistosomal efficacy against murine $S$. mansoni infection
}

\author{
Amr Radwan ${ }^{*} \mathbb{0}$, Naglaa M. El-Lakkany² ${ }^{2}$ Samia William³ ${ }^{3}$ Gina S. El-Feky ${ }^{4}$, Muhammad Y. Al-Shorbagy ${ }^{5,6}$, \\ Samira Saleh ${ }^{5}$ and Sanaa Botros ${ }^{2}$
}

\begin{abstract}
Background: Schistosomiasis is responsible for a considerable global disease burden. This work aimed to improve the therapeutic outcome of the only available antischistosomal drug worldwide, praziquantel (PZQ), by incorporating it into a novel carrier, "solid lipid nanoparticles (SLNs)", to enhance its solubility, bioavailability and efficacy. A simple, cost-effective method was used to prepare SLN-PZQ.

Results: Compared to market PZQ (M-PZQ), SLN-PZQ was more bioavailable, as denoted by higher serum concentrations in both normal and infected mice where elevated $\mathrm{K}_{\mathrm{a}}, \mathrm{AUC}_{0-24}, \mathrm{C}_{\text {max }}$ and $\mathrm{t}_{1 / 2 \mathrm{e}}$ with a decrease in $\mathrm{K}_{\mathrm{el}}$ were demonstrated. The AUC $\mathrm{C}_{0-24}$ for SLN-PZQ in normal and Schistosoma mansoni-infected groups was almost nine- and eight-fold higher, respectively, than that for M-PZQ in corresponding groups. In normal and S. mansoni-infected mice, SLN-PZQ was detectable in serum at $24 \mathrm{~h}$, while M-PZQ completely vanished $8 \mathrm{~h}$ post-treatment. Additionally, enhanced absorption with extended residence time was recorded for SLN-PZQ. Compared to M-PZQ, SLN-PZQ revealed superior antischistosomal activity coupled with enhanced bioavailability in all treated groups where higher percentages of worm reduction were recorded with all dosages tested. This effect was especially evident at the lower dose levels. The $\mathrm{ED}_{95}$ of SLN-PZQ was 5.29-fold lower than that of $\mathrm{M}-\mathrm{PZQ}$, with a significantly higher reduction in both the hepatic and intestinal tissue egg loads of all treated groups and almost complete disappearance of immature deposited eggs (clearly evident at the low dose levels).
\end{abstract}

Conclusions: SLN-PZQ demonstrated enhanced PZQ bioavailability and antischistosomal efficacy with a safe profile despite the prolonged residence in the systemic circulation.

Keywords: Bioavailability, Efficacy, Mice, Praziquantel, Schistosoma mansoni, Solid lipid nanoparticles

\section{Background}

Schistosomiasis, a neglected tropical parasitic disease, is endemic in more than 75 countries [1]. Over 200 million individuals are infected worldwide, and schistosomiasis is within the top ten diseases for years lived with disability in sub-Saharan countries [2]. Despite this considerable

\footnotetext{
*Correspondence: radwan.amro@gmail.com

${ }^{1}$ Research Department, Academy of Scientific Research and Technology, Cairo, Egypt

Full list of author information is available at the end of the article
}

disease burden, at present, there is no effective vaccine, the intermediate host is not always easily defeated and chemotherapy remains the primary approach for disease control. Praziquantel (PZQ) remains the only effective frontline drug to treat the parasite and is currently characterized by its exclusive and extensive use as an important antischistosomal drug [3]. Although mass administration campaigns of PZQ as well as preventive measures through chemotherapy have shown a significant impact on schistosomiasis, the efficacy concerns are debatable in addition to the possible development of drug 
resistance [4-7]. Since PZQ does not show a $100 \%$ cure rate $[8,9]$, the surviving worms might develop resistance quickly; hence, this resistance might be passed on to the next generations of Schistosoma [10, 11]. The failure to achieve complete cures in PZQ-treated populations may be linked to the insufficient long-lasting effect of PZQ and its low bioavailability, which is attributed to the hydrophobic nature of the drug $[11,12]$. PZQ is a class II compound (high permeability, low solubility) and is highly lipophilic. The drug crosses the gastrointestinal tract by passive diffusion to quickly reach the bloodstream and undergoes rapid metabolism [13, 14]. This rapid metabolism might account for the insusceptibility of juvenile and immature worms to PZQ in the systemic circulation and might raise concerns about the long-term impact of mass treatment campaigns. Larger doses or repetitive treatments were recommended for enhancing treatment efficacy [15], although these treatments might account for the higher frequency of side effects [16]. In a meta-analysis involving 273 clinical studies, the series of side effects reported were related to the recommended higher dose of PZQ [9] and may also be the main driver for the evolution of Schistosoma resistance to treatment. Moreover, repetitive treatments definitely represent a financial burden on developing countries, justifying the search for alternatives as well as the development of methods to overcome existing drug drawbacks.

PZQ in nanoformulation may overcome its known drawbacks (quick first pass metabolism in the liver) with its consequent reduced efficacy, specifically against the immature forms in the systemic circulation. Several promising drug delivery systems were examined for PZQ [17-20]. Incorporating drugs into nanocarriers, specifically "solid lipid nanoparticles (SLNs)", has a superior advantage over common nanoformulations with respect to drug targeting, release, long-shelf stability, low toxicity, better bioavailability and compatibility with several routes of administration [21, 22]. Moreover, SLNs could resolve drawbacks, including undesirable taste, possible irritation and gastrointestinal adverse reactions with high safety margins and high biocompatibility over other conventional nanoformulations [23].

In the present study, simple, cost-effective formulations of PZQ in solid lipid nanoparticles (SLN-PZQ) were tested in experimental murine schistosomiasis with the aim of enhancing PZQ solubility, bioavailability and efficacy.

\section{Methods}

\section{Experimental animals}

CD1 male Swiss albino mice, with an average weight of $20 \pm 2 \mathrm{~g}$, were bred and maintained at the Schistosome Biology Supply Center (SBSC) of Theodor Bilharz
Research Institute (TBRI), Giza, Egypt. All animal experiments were conducted with respect to guidelines for the care and use of laboratory animals of the National Institutes of Health $(\mathrm{NIH}, 1996)$ and its amendments.

\section{Drugs}

PZQ [Distocide; Egyptian International Pharmaceuticals Industries Co (EIPICO), Cairo, Egypt] tablets were ground into powder, marked as "market PZQ (M-PZQ)" and given orally as a suspension in $2 \%$ Cremophor-El (Sigma-Aldrich, St. Louis, MO, USA). Fresh batches of drug doses were administered by oral gavage using a stainless-steel oral cannula.

\section{Preparation of SLN-PZQ}

Different SLN-PZQ formulations were prepared (Table 1) using the pure form of PZQ (EIPICO). The lipid phase in SLN preparation consisted of variable ratios of plurol oleique (P.O.) to Labrafil, in addition to constant $0.1 \mathrm{mg}$ Lauroglycol 90 . These components were melted at $5{ }^{\circ} \mathrm{C}$ above the melting point of the lipid used, and PZQ was well dispersed therein to obtain a drug-lipid mixture. The drug-lipid mixture was sonicated for $30 \mathrm{~min}$ (Elmasonic S $30(\mathrm{H})$; Elma, Singen, Germany). An aqueous phase containing either $0.1,0.3$ and $0.5 \mathrm{mg}$ of Labrasol in $10 \mathrm{ml}$ of distilled water was heated up to the same temperature as the molten lipid phase, and the hot lipid phase was poured onto the hot aqueous phase with homogenization at 25,000 $\times$ rpm for $3 \mathrm{~min}$. PZQ-loaded SLNs were finally obtained by allowing hot nanoemulsions to cool to room temperature. Blank SLNs were prepared using the same variables but without the drug [24]. SLNs were lyophilized using a programmable freeze-dryer (alpha 1-4 LSC; Christ, Osterode am Harz, Germany).

\section{Characterization of SLN-PZQ}

\section{Particle size and polydispersity index (PDI)}

The size of the prepared SLNs and the PDI were measured after reconstitution with ultra-purified water using a particle size analyser (Zetasizer 2000; Malvern Instruments, Malvern, UK). Particle size measurement ensured the nanosize range of the prepared formulations, while the PDI validated the uniformity of the nanoparticle size distribution [25].

\section{Zeta potential}

As a quantitative guide to particle stability, the zeta potential of SLNs was determined by measuring electrophoretic mobility using a zeta sizer (Zetasizer 2000). Prior to the electrophoretic mobility measurements, all the samples were diluted with ultra-purified water, and the measurements were carried out at $25{ }^{\circ} \mathrm{C}$. The conversion of electrophoretic mobility to the zeta potential 
Table 1 Composition of solid lipid nanoparticle formulations and their physicochemical properties when loaded with PZQ

\begin{tabular}{|c|c|c|c|c|c|c|c|}
\hline \multirow[t]{2}{*}{ SLN formula } & \multicolumn{3}{|c|}{ Composition of SLN formulations } & \multicolumn{4}{|c|}{ Physicochemical properties } \\
\hline & $\begin{array}{l}\text { Labrafil: Plurol } \\
\text { oleique }\end{array}$ & $\begin{array}{l}\text { Lauroglycol } 90 \\
(\mathrm{mg})\end{array}$ & Labrasol (mg) & Particle size $(\mathrm{nm})^{\mathrm{a}}$ & PDI & $\mathrm{ZP}(\mathrm{mV})$ & $\mathrm{EE}(\%)^{\mathrm{a}}$ \\
\hline $\mathrm{F} 1$ & $1: 1$ & 0.1 & 0.1 & $285.45 \pm 4.39$ & 0.843 & -14.5 & $5.46 \pm 0.23$ \\
\hline F2 & $1: 3$ & 0.1 & 0.1 & $302.3 \pm 5.27$ & 0.657 & -17.3 & $3.02 \pm 0.11$ \\
\hline F3 & $1: 5$ & 0.1 & 0.1 & $123.5 \pm 2.19$ & 0.675 & -18.5 & $32.04 \pm 2.19$ \\
\hline F4 & $1: 1$ & 0.1 & 0.2 & $140.4 \pm 2.49$ & 0.654 & -23.4 & $31.12 \pm 3.02$ \\
\hline F5 & $1: 3$ & 0.1 & 0.2 & $155.3 \pm 3.01$ & 0.765 & -24.6 & $54.56 \pm 4.28$ \\
\hline F6 & $1: 5$ & 0.1 & 0.2 & $133.6 \pm 8.22$ & 0.546 & -26.4 & $91.26 \pm 3.39$ \\
\hline F7 & $1: 1$ & 0.1 & 0.4 & $105.3 \pm 4.39^{*}$ & 0.314 & -35.2 & $109.21 \pm 2.83^{*}$ \\
\hline F8 & $1: 3$ & 0.1 & 0.4 & $87.32 \pm 5.19^{*}$ & 0.432 & -38.3 & $101.12 \pm 3.28^{*}$ \\
\hline F9 & $1: 5$ & 0.1 & 0.4 & $118.4 \pm 7.10^{*}$ & 0.321 & -35.4 & $100.23 \pm 1.46^{*}$ \\
\hline
\end{tabular}

Notes: Praziquantel-loaded SLNs were composed of plurol oleique (P.O.), Labrafil and Lauroglycol 90 as core matrices Labrasol in $10 \mathrm{ml}$ distilled water was incorporated at concentrations of $0.1,0.2$ or $0.4 \mathrm{mg}$ to each of the three Labrafil:plurol oleique ratios. Physiochemical properties were assessed for each formulation

a Values represent the means \pm standard deviation (SD)

* Significant differences from the different SLN formulations at $P<0.05$

Abbreviations: SLN, solid lipid nanoparticle; PDI, polydispersity index; ZP, zeta potential; EE, entrapment efficiency

was performed using the following Helmholtz-Smoluchowski equation $[26]: \zeta=\mathrm{E}(4 \pi \eta / \varepsilon)$ where $\zeta$ is the zeta potential $(\mathrm{mV}), \mathrm{E}$ is the electrophoretic mobility, $\eta$ is the viscosity of the dispersion medium (water $0.8904 \mathrm{cp}$ ) and $\varepsilon$ is the dielectric constant of the solvent (water, 78.54).

\section{Entrapment efficiency (EE)}

The prepared nanoparticle dispersion was centrifuged at $14,000 \times \mathrm{rpm}$ for $1 \mathrm{~h}$ at $0{ }^{\circ} \mathrm{C}$ using a cooling centrifuge (Sigma-3k30; Sigma-Aldrich, Munich, Germany). The supernatant was then analysed for the free drug content. The concentration of PZQ in the supernatant was determined by UV-visible spectrophotometry at 263.8 $\mathrm{nm}$. Entrapment efficiency (EE) was calculated using the following equation: $\mathrm{EE}(\%)=(\mathrm{PZQ}$ initial-PZQ supernatant) / PZQ initial $\times 100$.

\section{In vitro release studies}

To assess the percentage of drug released during the transit time in the stomach, we examined the in vitro release of formulations exhibiting optimum properties regarding physiochemical characteristics. The in vitro release of PZQ-loaded SLNs was examined in $900 \mathrm{ml}$ of $0.1 \mathrm{~N} \mathrm{HCl}$, and the temperature was maintained at $37{ }^{\circ} \mathrm{C}$ with a paddle operated at $50 \times \mathrm{rpm}$. The formulations were secured by clamps in a non-rate controlling dialysis bags. An aliquot of $5 \mathrm{ml}$ was withdrawn at pre-determined intervals of $0.25,0.5,1.5$ and $2 \mathrm{~h}$ and then substituted with $5 \mathrm{ml}$ of $0.1 \mathrm{~N} \mathrm{HCl}$. This process was performed using a USP dissolution tester (apparatus II, model DT-D; Erweka Apparatebau $\mathrm{GmbH}$, Heusenstamm, Germany). Aliquots were analysed spectrophotometrically at $263.8 \mathrm{~nm}$.

\section{Pharmacokinetic studies}

The formulation of optimum properties regarding physicochemical characteristics and in vitro release was selected for pharmacokinetic studies. Two batches comprising 220 normal mice were used for the assessment of pharmacokinetics for "M-PZQ" and "SLN-PZQ" after their administration in a single oral dose of $500 \mathrm{mg} / \mathrm{kg}$. Each batch was subdivided into 11 groups of 10 mice each according to time of sacrifice (by decapitation), i.e. $2,5,15,30 \mathrm{~min}$ and $1,2,4,6,8,14$ and $24 \mathrm{~h}$ after drug administration. Two other batches of S. mansoni-infected mice, matching the number of normal animals, followed the same procedure. At times of sacrifice, blood samples were collected, and sera were separated and stored at $-70{ }^{\circ} \mathrm{C}$ until assayed. Extraction and estimation of PZQ in the different serum samples were performed using high-performance liquid chromatography (HPLC) on a series 3000 Dionex Ultimate (Dionex, Amsterdam, The Netherlands) adhering to a modification of the method described by Xiao et al. [27]. The column flow rate was $2 \mathrm{ml} / \mathrm{min}$, the mobile phase used was $42 \%$ acetonitrile/ $\mathrm{H}_{2} \mathrm{O}$ and the detector wavelength was set at $210 \mathrm{~nm}$. For PZQ concentration estimation, $0.5 \mathrm{ml}$ of sera was extracted with 3-ml aliquots of ethyl acetate and centrifuged at $1850 \times g$ for $15 \mathrm{~min}$. Two-milliliter aliquots of the extracts were evaporated to dryness at $25^{\circ} \mathrm{C}$ under a nitrogen stream, and the residue was then re-suspended in $200 \mu \mathrm{l}$ of acetonitrile and shaken on a vortex mixer for $1 \mathrm{~min}$. The sample $(25 \mu \mathrm{l})$ was then injected into a Nova Pak C18, $60 \AA$ A $4 \mu \mathrm{m}, 3.9 \times 150 \mathrm{~mm}$ HPLC column (Millipore Co., Milford, MA, USA) equipped with a series 200 programmable multi-wavelength detector (Perkin 
Elmer; Norwalk, CT, USA). The calibration curve was linear between 0 and $3.2 \mu \mathrm{g} / \mathrm{ml}$ (correlation coefficient $(r)=0.9984)$. The coefficients of variation for within- and inter-day reproducibility were $1-4 \%$ depending on the drug concentration.

Pharm PCS software v.4.2 was used for computing pharmacokinetic parameters based on the classic method of residuals and the least square technique for curve fitting [28]. Coefficients and exponents of the fitted function were used to calculate the theoretical maximum concentration $\left(\mathrm{C}_{\max }\right)$ and the time to maximum concentration $\left(\mathrm{T}_{\max }\right)$ of PZQ. The corresponding elimination half-lives $\left(t_{1 / 2 \mathrm{e}}\right)$ were calculated as $\ln 2$ /elimination rate constant $\left(k_{\mathrm{el}}\right)$. The area under the serum concentrationtime curve $\left(\mathrm{AUC}_{0-24 \mathrm{~h}}\right)$ was calculated by applying the linear trapezoidal method.

\section{Antischistosomal efficacy}

\section{Schistosoma mansoni infection of animals}

Schistosoma mansoni cercariae, obtained from laboratory-bred infected Biomphalaria alexandrina snails, were used to infect mice. The body immersion technique was used for the infection with $80 \pm 10$ cercariae per mouse [29].

\section{Animal groups}

Schistosoma mansoni-infected mice were randomly allocated into two batches. Seven weeks post-infection, the animals of each batch were subdivided into six groups of 6-8 mice each. Five of these groups received either M-PZQ or SLN-PZQ in total oral doses of 62.5, 125, 250, 500 or $1000 \mathrm{mg} / \mathrm{kg}$ divided equally on 5 consecutive days, while the sixth group was left untreated as the respective control.

\section{Recovery of S. mansoni worms and estimation of PZQ ED $D_{95}$}

Two weeks after the end of treatment, mice were sacrificed by decapitation, and the hepatic and portomesenteric vessels were perfused to recover and count worms, taking care to separate hepatic from portomesenteric worms [30]. The percent worm reduction was calculated to estimate the PZQ 95\% effective dose $\left(\mathrm{ED}_{95}\right)$ [5]. The percent reduction in worm burden in each treated group was calculated using the following equation: No. of worms in the control group - No. of worms in the treated group/No. of worms in the control group $\times 100$. The $\mathrm{ED}_{95}$ (effective dose required to kill $95 \%$ of adult worms) was calculated using Probit analysis of a plot of worm reduction percentages versus amounts of drug administered using GraphPad Prism software v.6.0.
Determination of tissue egg load and oogram profile (percentage of eggs in different developmental stages)

Portions of the liver and intestine were examined to determine the number of eggs per gram of liver and intestine tissue [31]. Another portion of the small intestine was used to determine the percentage of egg developmental stages. A dose of a drug was considered to have a definite activity against $S$. mansoni when the oogram revealed $50 \%$ or more mature eggs and the absence of one or more stages of immature eggs [32].

\section{Statistical analysis}

The results are expressed as the mean \pm SEM. One-way analysis of variance (ANOVA) followed by Tukey's posthoc test was performed using GraphPad Prism software to detect the significance of differences between the means of different groups. The results were considered significant if $P<0.05$.

\section{Results}

Preparation of SLN-PZQ

PZQ-loaded SLN dispersions were composed of P.O., Labrafil and Lauroglycol 90 as core matrices. Despite the liquid nature of the used lipids, formulations showed an emulsion appearance, which was attributed to the polyoxyl nature of Labrafil that can form hydrogen bonds with water, resulting in a network-like structure capable of swelling (Table 1).

\section{Characterization of SLN-PZQ}

\section{Particle size and polydispersity index (PDI)}

The particle sizes of all prepared SLNs ranged between 87.32-302.3 nm. No general trend was observed for the increase or decrease in particle size with increasing Labrafil:P.O. ratios in each of the studied Labrasol concentrations. However, increasing the concentration of Labrasol from $0.1 \mathrm{mg}$ to $0.4 \mathrm{mg}$ shifted the average particle size to significantly smaller values (ANOVA, $\left.F_{(3,27)}=9.34, P=0.023\right)$. The polydispersity index is a ratio that provides information about the homogeneity of particle size distribution in a given system. Generally, the prepared formulations showed high PDIs except for formulas F7 and F9 where narrow dispersity was recorded (Table 1).

\section{Zeta potential}

Zeta potential is an indicative of probable physical stability of a formulation. Nanoparticles with zeta potential values more than $25 \mathrm{mV}$ showed high degrees of stability [33]. Formulas with the highest concentration of Labrasol (F7, F8 and F9) showed significantly higher zeta potential (ANOVA, $F_{(3,27)}=8.57, P=0.026$ ) than did other 
formulations (Table 1). Due to the negative charge of the lipid phase, the zeta potential of all formulations was negative.

\section{Entrapment efficiency (EE)}

Entrapment efficiency is used to assess the capability of the prepared SLNs to efficiently entrap PZQ. All SLN formulations prepared with a higher concentration of surfactant showed significantly higher EE (F7: 109.2\%; F8: 101.12\%; and F9: 100.23\%). Additionally, increasing the particle size above the average range (F1: $285.45 \mathrm{~nm}$ and F2: $302.3 \mathrm{~nm}$ ) drastically decreased the EE (Table 1).

\section{In vitro release studies}

Formulas F6, F7 and F8 exhibited optimum properties regarding particle size, drug entrapment and physical

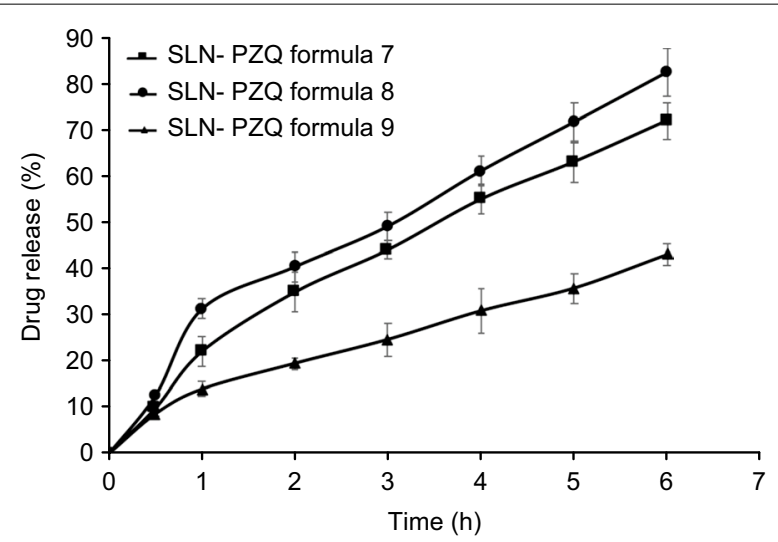

Fig. 1 In vitro percentage PZQ released over time from solid lipid nanoparticle-PZQ formulations. In vitro release studies were performed to select SLN formulations with optimum physiochemical properties (Formulas 7, 8 and 9). This selection was performed using a USP dissolution tester, and aliquots were analysed spectrophotometrically. Values are presented as the means \pm SD. Abbreviation: SLN-PZQ, praziquantel-loaded solid lipid nanoparticle stability and were subjected to in vitro release studies. In vitro release, expressed by transit time in the stomach, revealed that F9 possessed the largest particle size $(118.4 \mathrm{~nm})$ and showed the lowest percentage of drug release over $6 \mathrm{~h}$, while F8 with a smaller diameter (87.32 $\mathrm{nm}$ ) showed a higher percentage of drug release (Fig. 1). F8 showed $31.18 \%$ burst release at $1 \mathrm{~h}$, whereas F7 and F9 did not express the same profile. F7 showed the best physicochemical characteristics and was selected for the in vivo biological investigation involving bioavailability and efficacy studies.

\section{Pharmacokinetic studies of SLN-PZQ and M-PZQ in normal and S. mansoni-infected mice}

Compared to M-PZQ, SLN-PZQ showed higher PZQ concentrations in the sera of both normal and S. mansoni-infected mice, as demonstrated by the elevated absorption rate constant $\left(\mathrm{K}_{\mathrm{a}}\right), \mathrm{AUC}_{0-24}, \mathrm{C}_{\max }$, and $\mathrm{t}_{1 / 2 \mathrm{e}}$ with a decrease in $k_{\mathrm{el}}$ (Table 2). The values obtained for $\mathrm{AUC}_{0-24}$ for the SLN-PZQ group were approximately 9-fold and 8-fold higher than those recorded for the M-PZQ group in both normal and S. mansoni-infected mice, respectively. Compared to mice treated with M-PZQ, normal and S. mansoni-infected mice treated with SLN-PZQ showed a significant increase in $K_{a}, C_{\max }$ and $\mathrm{t}_{1 / 2 \mathrm{e}}$ by 2.14- and 1.99-fold; 2.33- and 2.64-fold; and 6.41 and 6.17 -fold, respectively, while $K_{\mathrm{el}}$ significantly decreased by 5.77 - and 6.30 -fold, respectively (Table 2 ). The serum concentration of SLN-PZQ was detectable at $24 \mathrm{~h}$, while that of M-PZQ vanished $8 \mathrm{~h}$ post-treatment in both normal and S. mansoni-infected mice (Fig. 2).

\section{Antischistosomal efficacy}

At 14 days post-treatment, the percent total worm reduction was higher in $S$. mansoni-infected mice treated with rising doses of SLN-PZQ than in mice treated with M-PZQ (Table 3), but the differences (86.5, 94.4 and

Table 2 Pharmacokinetic parameters of SLN-PZQ vs market PZQ at a single dose of $500 \mathrm{mg} / \mathrm{kg}$

\begin{tabular}{|c|c|c|c|c|c|c|c|}
\hline \multirow[t]{2}{*}{ Animal group } & \multirow[t]{2}{*}{ Treatment } & \multicolumn{6}{|c|}{ Pharmacokinetic parameters (mean \pm SEM) } \\
\hline & & $\mathrm{k}_{\mathrm{a}}\left(\mathrm{h}^{-1}\right)$ & $k_{e l}\left(h^{-1}\right)$ & $t_{1 / 2 e}\left(h^{-1}\right)$ & $\mathrm{AUC}(\mu \mathrm{g} \mathrm{h} / \mathrm{ml})$ & $C_{\max }(\mu \mathrm{g} / \mathrm{ml})$ & $T_{\max }(h)$ \\
\hline \multirow[t]{2}{*}{ Normal } & M-PZQ & $6.52 \pm 0.05$ & $1.27 \pm 0.01$ & $0.55 \pm 0.00$ & $14.03 \pm 0.98$ & $15.98 \pm 1.46$ & $0.14 \pm 0.04$ \\
\hline & SLN-PZQ & $13.98 \pm 1.30^{*}$ & $0.22 \pm 0.03^{*}$ & $3.53 \pm 0.60^{*}$ & $123.75 \pm 11.39^{*}$ & $37.24 \pm 2.07^{*}$ & $0.29 \pm 0.04$ \\
\hline \multirow[t]{2}{*}{ S. mansoni-infected } & M-PZQ & $11.23 \pm 0.86^{\$}$ & $0.63 \pm 0.01^{\dagger}$ & $1.11 \pm 0.02^{\dagger}$ & $34.61 \pm 2.50^{+}$ & $24.31 \pm 1.19$ & $0.14 \pm 0.04$ \\
\hline & SLN-PZQ & $22.34 \pm 0.67^{\#+}$ & $0.10 \pm 0.01^{\#+}$ & $6.85 \pm 0.60^{\#+}$ & $286.33 \pm 13.54^{\# \dagger}$ & $64.29 \pm 7.78^{\#+}$ & $0.22 \pm 0.03$ \\
\hline
\end{tabular}

* Significant differences between SLN-PZQ and M-PZQ in normal treated mice at $P<0.05$

\# Significant differences between SLN-PZQ and M-PZQ in S. mansoni-infected treated mice at $P<0.05$

+ Significant differences of SLN-PZQ or M-PZQ in S. mansoni-infected mice compared to respective normal mice at $P<0.05$ 
96.1\% for SLN-PZQ vs 51.5, 72.2 and 89.1\%, for M-PZQ) were significant with the small doses tested $(62.5 \mathrm{mg} /$ $\mathrm{kg}$ : ANOVA, $\quad F_{(2,15)}=18.45, \quad P<0.0001 ; 125 \mathrm{mg} / \mathrm{kg}$ :

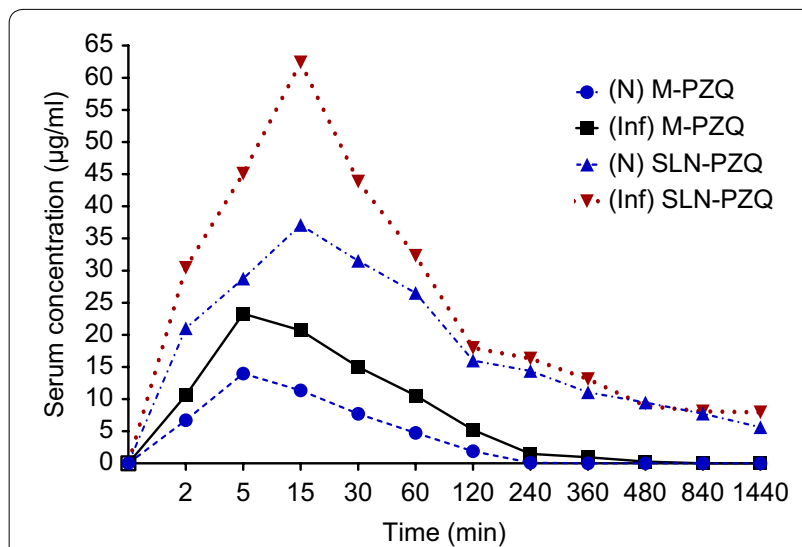

Fig. 2 Serum concentration-time curves of SLN-PZQ and or market PZQ at a single dose of $500 \mathrm{mg} / \mathrm{kg}$. Abbreviations: (N) M-PZQ, serum concentration of market praziquantel in normal mice; (Inf) M-PZQ, serum concentration of market praziquantel in S. mansoni-infected mice; (N) SLN-PZQ, serum concentration of solid lipid nanoparticle praziquantel in normal mice; (Inf) SLN-PZQ, serum concentration of solid lipid nanoparticle praziquantel in S. mansoni-infected mice
ANOVA, $F_{(2,15)}=8.36, P=0.0036 ; 250 \mathrm{mg} / \mathrm{kg}:$ ANOVA, $\left.F_{(2,15)}=6.92, P=0.0074\right)$, respectively. The $\mathrm{ED}_{95}$ of SLNPZQ was 5.29-fold lower than that of M-PZQ (176.89 $\mathrm{mg} / \mathrm{kg}$ vs $936.13 \mathrm{mg} / \mathrm{kg}$ for M-PZQ) (Fig. 3). Moreover, compared to M-PZQ treatment, SLN-PZQ treatment resulted in a significantly higher reduction in both the hepatic tissue egg load at the higher doses tested and in the intestinal tissue egg load with all doses recorded (Fig. 4a, b). Compared to M-PZQ, all doses of SLN-PZQ resulted in the complete absence of immature eggs in the oogram pattern (Fig. 5). M-PZQ started to show the same finding when the $250 \mathrm{mg} / \mathrm{kg}$ dose was tested. Compared to M-PZQ, SLN-PZQ significantly increased the percentage of dead eggs, and the difference was significant (ANOVA, $F_{(2,15)}=9.55, P=0.0021$ ) with the lowest dose tested $(62.5 \mathrm{mg} / \mathrm{kg})$. Although no significant differences were observed at the higher doses of SLN-PZQ tested, an apparently higher reduction in the percentages of total mature eggs was recorded after SLN-PZQ treatment than after M-PZQ treatment (Fig. 5).

Table 3 Worm distribution in the hepatic and portomesenteric vessels of S. mansoni-infected treated mice

\begin{tabular}{|c|c|c|c|c|c|c|}
\hline Dose (mg/kg) & Animal group & Total no. of worms & Total no. of male worms & $\begin{array}{l}\text { Total no. of } \\
\text { female worms }\end{array}$ & $\begin{array}{l}\text { Total no. of } \\
\text { hepatic worms }\end{array}$ & $\begin{array}{l}\text { Total no. of } \\
\text { portomesenteric } \\
\text { worms }\end{array}$ \\
\hline Control & & $21.00 \pm 0.59$ & $12.44 \pm 1.6$ & $8.56 \pm 1.0$ & $5.33 \pm 1.14$ & $15.66 \pm 1.98$ \\
\hline \multirow[t]{2}{*}{62.5} & M-PZQ & $\begin{array}{l}10.17 \pm 0.4 \\
(51.59)^{*}\end{array}$ & $\begin{array}{l}6.33 \pm 1.0 \\
(49.09)^{*}\end{array}$ & $\begin{array}{l}3.83 \pm 0.7 \\
(55.22)^{*}\end{array}$ & $4.66 \pm 0.8$ & $5.5 \pm 0.62^{*}$ \\
\hline & SLN-PZQ & $\begin{array}{l}2.83 \pm 0.7 \\
(86.51)^{* \dagger}\end{array}$ & $\begin{array}{l}2.67 \pm 0.7 \\
(78.56)^{* \dagger}\end{array}$ & $\begin{array}{l}0.17 \pm 0.1 \\
(98.05)^{* \dagger}\end{array}$ & $1.00 \pm 0.26^{* \dagger}$ & $1.83 \pm 0.60^{* \dagger}$ \\
\hline \multirow[t]{2}{*}{125} & M-PZQ & $\begin{array}{l}5.83 \pm 0.7 \\
(72.22)^{*}\end{array}$ & $\begin{array}{l}3.83 \pm 1.0 \\
(69.19)^{*}\end{array}$ & $\begin{array}{l}1.33 \pm 0.2 \\
(84.42)^{*}\end{array}$ & $2.83 \pm 0.98^{*}$ & $2.33 \pm 0.76^{*}$ \\
\hline & SLN-PZQ & $\begin{array}{l}1.17 \pm 0.4 \\
(94.44)^{* \dagger}\end{array}$ & $\begin{array}{l}0.83 \pm 0.3 \\
(92.50)^{* \dagger}\end{array}$ & $\begin{array}{l}0.33 \pm 0.2 \\
(95.33)^{* \dagger}\end{array}$ & $0.33 \pm 0.21^{* \$}$ & $0.83 \pm 0.98^{*}$ \\
\hline \multirow[t]{2}{*}{250} & M-PZQ & $\begin{array}{l}2.29 \pm 0.1 \\
(89.10)^{*}\end{array}$ & $\begin{array}{l}2.0 \pm 0.2 \\
(83.92)^{*}\end{array}$ & $\begin{array}{l}0.29 \pm 0.1 \\
(96.66)^{*}\end{array}$ & $0.57 \pm 0.4^{*}$ & $0.57 \pm 0.20^{*}$ \\
\hline & SLN-PZQ & $\begin{array}{l}0.83 \pm 0.3 \\
(96.05)^{* \dagger}\end{array}$ & $\begin{array}{l}0.67 \pm 0.2 \\
(94.64)^{*}\end{array}$ & $\begin{array}{l}0.17 \pm 0.1 \\
(98.05)^{*}\end{array}$ & $0.33 \pm 0.5^{*}$ & $0.33 \pm 0.20^{*}$ \\
\hline \multirow[t]{2}{*}{500} & M-PZQ & $\begin{array}{l}1.43 \pm 0.2 \\
(93.19)^{*}\end{array}$ & $\begin{array}{l}0.86 \pm 0.3 \\
(93.11)^{*}\end{array}$ & $\begin{array}{l}0.57 \pm 0.2 \\
(93.32)^{*}\end{array}$ & $1.17 \pm 0.38^{*}$ & $0.29 \pm 0.49^{*}$ \\
\hline & SLN-PZQ & $\begin{array}{l}0.50 \pm 0.3 \\
(97.62)^{*}\end{array}$ & $\begin{array}{l}0.33 \pm 0.3 \\
(97.32)^{*}\end{array}$ & $\begin{array}{l}0.33 \pm 0.2 \\
(98.05)^{*}\end{array}$ & $0.5 \pm 0.34^{*}$ & $0.00 \pm 0.00^{*}$ \\
\hline \multirow[t]{2}{*}{1000} & M-PZQ & $\begin{array}{l}0.75 \pm 0.3 \\
(96.43)^{*}\end{array}$ & $\begin{array}{l}0.63 \pm 0.3 \\
(94.98)^{*}\end{array}$ & $\begin{array}{l}0.13 \pm 0.1 \\
(98.54)^{*}\end{array}$ & $0.75 \pm 0.31^{*}$ & $0.00 \pm 0.00^{*}$ \\
\hline & SLN-PZQ & $\begin{array}{l}0.33 \pm 0.2 \\
(98.43)^{*}\end{array}$ & $\begin{array}{l}0.33 \pm 0.2 \\
(97.32)^{*}\end{array}$ & $\begin{array}{l}0.00 \pm 0.0 \\
(100.0)^{*}\end{array}$ & $0.17 \pm 0.16^{*}$ & $0.16 \pm 0.16^{*}$ \\
\hline
\end{tabular}

Notes: Data are presented as the means \pm SEM. $n=6-8$ mice per group. Mice were sacrificed 14 days after treatment. Number in parentheses represents the percentage worm reduction versus the infected untreated control. Percentage of worm reduction $=$ (mean number of worms in control group - mean number of worms in treated group)/mean number in control group $\times 100$

* Significant differences of SLN-PZQ or M-PZQ versus parallel infected untreated control at $P<0.05$

+ Significant differences of SLN-PZQ versus parallel values of M-PZQ at $P<0.05$

Abbreviations: SLN-PZQ, solid lipid nanoparticle praziquantel; $M-P Z Q$, market praziquantel 


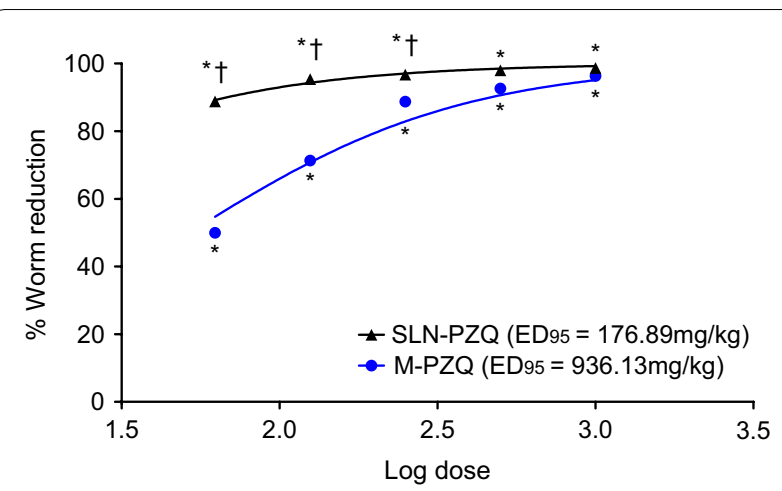

Fig. 3 Computer-adjusted drug dose-response curves for M-PZQ and SLN-PZQ. The curves were fitted to results calculated using GraphPad Prism software v.6.01 and were plotted assuming that all had a minimum of $0 \%$ and a maximum of $100 \%$. *Significant worm reduction in S. mansoni-infected mice treated with SLN-PZQ and $\mathrm{M}-\mathrm{PZQ}$ vs the corresponding infected untreated controls at $\mathrm{P}<0.05$. ${ }^{\dagger}$ Significant worm reduction in $\mathrm{S}$. mansoni-infected mice treated with SLN-PZQ vs that in mice treated with $M-P Z Q$ at $P<0.05$. Abbreviations: SLN-PZQ, solid lipid nanoparticle praziquantel; M-PZQ, market praziquantel; $\mathrm{ED}_{95}$, effective dose required to kill $95 \%$ of adult worms

\section{Discussion}

The search for innovative drugs is paramount in medicine, but the challenge is greater for neglected tropical diseases where little is invested in developing such treatments. The pipeline is almost dry for tropical diseases of the poor due to the marginal or almost non-existent profits and the needs are unmet for these medical conditions [34] where the costs for the discovery and development are too high to achieve therapeutic excellence and capture market economies [35].

This work focused on improving the biological characteristics of the existing drug to treat schistosomiasis, PZQ. Working on existing drugs simplifies and shortens the long and difficult process of drug discovery. On average, it takes at least ten years for a new medicine to complete the journey from initial discovery to the marketplace [36]. Although PZQ is endowed with excellent properties, e.g. effective against the main schistosomes pathogenic for humans with almost minimal side effects [37], drug efficacy is a concern because a $100 \%$ cure rate has not been achieved. Additionally, there is fear of worms surviving this treatment and potentially passing to the next generation leading to development of resistance. In addition, the drug's poor solubility in water and consequently low absorption restricts its delivery via the oral route $[38,39]$. PZQ is rapidly metabolized with less efficacy against immature worms, and large drug doses are required to achieve a sufficient concentration in larval tissue. In the present study, to overcome the drug drawbacks, we used SLNs were used as a delivery system for
PZQ. To assess the bioavailability and efficacy of SLN$P Z Q$, we examined the bioavailability of the new formulation in vivo in normal and S. mansoni-infected mice, while the efficacy of SLN-PZQ was studied in vivo using $S$. mansoni-infected mice and compared to that of conventional market PZQ.

SLNs as a delivery system have the advantage of increasing the surface area and quantum effects, thus enhancing the physicochemical characteristics, involving reactivity, strength, electrical characteristics and in vitro behaviour. Nine PZQ delivery systems of different SLN compositions (Labrafil/Lauroglycol) were primarily prepared to select the most promising formula with respect to physiochemical characteristics. Assessing the physicochemical characteristics of particle size, drug release, zeta potential and EE revealed that formula 7 with medium-sized particles, high EE, high stability, and particle uniformity is expected to show gradual, persistent drug release [40, 41]. This SLN-PZQ formulation showed a particle size of $105 \mathrm{~nm}$, which is smaller than other particles used in the in vitro studies of PZQ-loaded solid lipid nanoparticles against S. mansoni [42]. Particle sizes smaller than $400 \mathrm{~nm}$ reportedly improve the bioavailability of drugs [43]. The high concentrations of nonionic surfactant (Labrasol) through its steric properties enhanced the stability [44] of these nanosized particles, as shown by the higher zeta potential values for SLNPZQ formula 7. The surfactant used lowers the surface tension at the interface of the particles [45], causing partitioning of particles, hence resulting the formation of stabilized nanoparticles with smaller size and larger surface area. Notably, although formula 8 showed a higher drug release profile, the $31.18 \%$ burst release at $1 \mathrm{~h}$ in addition to the higher PDI affected its stability profile [46].

In the present study, pharmacokinetic assessment of both M-PZQ and SLN-PZQ in normal and S. mansoniinfected mice showed enhanced PZQ bioavailability of both M-PZQ and SLN-PZQ in the S. mansoni-infected groups. These results are in agreement with previous experimental studies in mice $[17,18,47,48]$ as well as in human patients infected with $S$. mansoni $[49,50]$. This enhancement might be related to the inflammatory reaction as a result of egg deposition [51], causing inhibition of cytochrome P450 (CYP450) and CYP450 reductase activities that were recorded in mice and human patients infected with $S$. mansoni [52, 53]. SLN-PZQ showed more absorption, bioavailability and higher serum concentrations than did M-PZQ, as denoted by elevated $\mathrm{K}_{\mathrm{a}}, \mathrm{AUC}_{0-24}, \mathrm{C}_{\text {max }}$, and $\mathrm{t}_{1 / 2 \mathrm{e}}$ with a decrease in $\mathrm{k}_{\mathrm{el}}$. The $\mathrm{AUC}_{0-24}$ for the SLN-PZQ groups were almost 9- and 8-fold higher than those for M-PZQ in corresponding groups of normal and infected mice, respectively. In addition, SLN-PZQ showed increases 

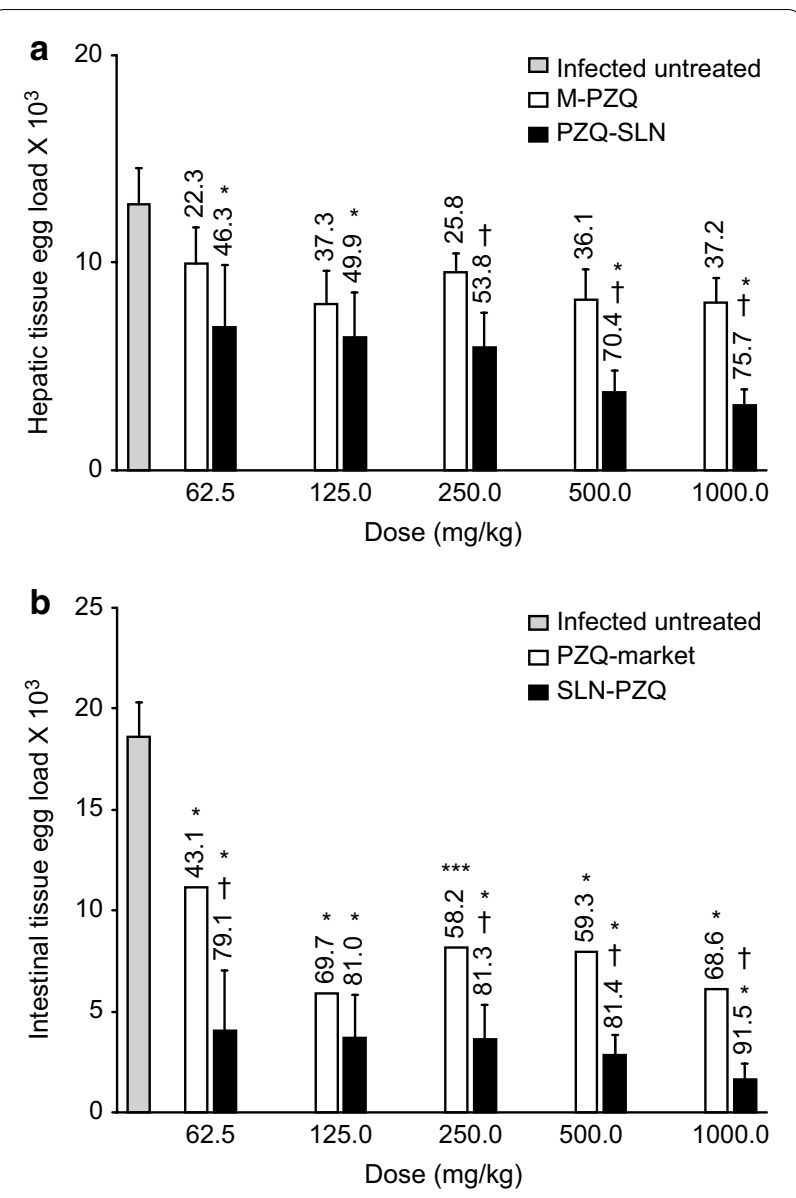

Fig. 4 Hepatic (a) and intestinal (b) tissue egg-load in infected mice treated with M-PZQ or SLN-PZQ. Mice were sacrificed 14 days after treatment. Data are presented as the means \pm SEM. $n=6-8$ mice per group. Number in parentheses represents the percentages of egg reduction vs infected untreated control. *Significant difference vs infected untreated control at $P<0.05$. 'Significant difference between SLN-PZQ and M-PZQ treatment at P $<0.05$. Abbreviations: SLN-PZQ, solid lipid nanoparticle praziquantel; M-PZQ, market praziquantel

in $\mathrm{C}_{\max }$ and $\mathrm{t}_{1 / 2 \mathrm{e}}$ by 2.33- and 2.61- and 6.4- and 6.17fold while $\mathrm{k}_{\mathrm{el}}$ decreased by 5.77 - and 6.30 -fold in corresponding groups of normal and infected mice, respectively. Improved dissolution of PZQ when administered in the SLN formulation was demonstrated in this work where the $\mathrm{K}_{\mathrm{a}}$ was increased by 2.14- and 1.99-fold compared with that in the M-PZQ formulation in corresponding groups of normal and infected mice, respectively. The improved dissolution of PZQ recorded is expected to enhance drug absorption as well as increase the residence period of the drug in the systemic circulation, hence prolonging the exposure of the parasite to the drug. The serum concentration of SLN-PZQ was detectable $(7.96 \mu \mathrm{g} / \mathrm{ml})$ in $S$. mansoniinfected mice $24 \mathrm{~h}$ after administration, while M-PZQ completely disappeared $8 \mathrm{~h}$ post-treatment. Additionally, a remarkable extended release pattern of SLN-PZQ has been reported and related to its enhanced bioadhesive nature to the wall of the gastrointestinal tract while benefiting from lipid protection in less exposure to enzymatic degradation [41]. This finding was revealed by a 6.4-fold increase in the serum $t_{1 / 2 \mathrm{e}}$ of SLN-PZQ compared to that of $\mathrm{M}-\mathrm{PZQ}$ in normal and infected mice. The strikingly increased $C_{\max }$ following the administration of SLN-PZQ is consistent with previous studies showing elevated plasma concentrations of SLN-PZQ $[41,54]$. The elevated $C_{\max }$ is also related to the possible high PZQ eruption release from the outer shell of SLNs at the initial phase [41]. By contrast, when nanoparticles were loaded in poly methyl methacrylate (PMMA), a 3-fold lower $\mathrm{C}_{\max }$ value of PZQ nanoparticles was reported compared to that of conventional PZQ nanoparticles. This result was attributed to the non-bioadhesive nature of PMMA and the incomplete release of the drug from the polymer matrix [19]. The particle surface properties in addition to the uniformity and proximity of the drug-loaded nanoparticles to the absorptive region of the gastrointestinal tract seem to govern the residence time, hence decreasing the time the drug remained in plasma, resulting in a low plasma concentration, as in the case of PMMA [55]. In this respect, it is important to highlight that the different preparation techniques together with the characterization of physical and chemical properties of the material used as a matrix for nanoparticle systems could interfere with nanoparticle drug absorption [56].

In the present study, the pharmacokinetic results revealed a delayed release effect of SLN-PZQ over $\mathrm{M}-\mathrm{PZQ}$ in both normal and infected mice. These findings are aligned with studies revealing a significant increase in $\mathrm{T}_{\max }$ of the SLN suspension of PZQ [41] and contradicting other studies that showed comparable $T_{\max }$ values of PZQ nanoparticles and conventional PZQ [19].

In this work, it was essential to examine the biological activities of this new formulation and whether this enhanced bioavailability results in higher efficacy in a model of murine schistosomiasis. In vivo studies of the efficacy of SLN-PZQ in schistosomiasis are limited, and the conducted in vitro studies focused on examining the possible enhanced physicochemical characteristics $[41,42]$. With respect to other parasitic infections, SLN formulations have shown promising findings over conventional PZQ in cestodal infection with the use of a low dose $(5 \mathrm{mg} / \mathrm{kg})$ in dogs infected with Echinococcus granulosus [54]. Additionally, using nanoprecipitation, a PZQ nanosuspension showed better efficacy against the cysticerci of the cestode parasite Taenia crassiceps [20]. In the present study, the enhanced bioavailability of PZQ 


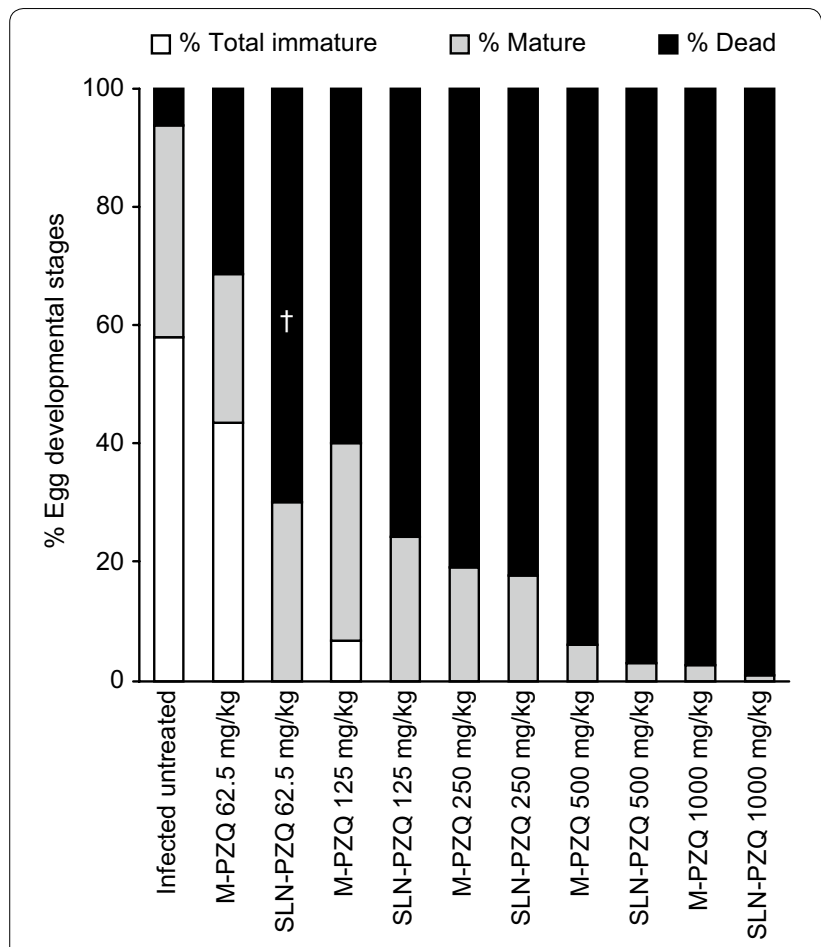

Fig. 5 Percentage egg developmental stages (oogram pattern) in infected mice treated with SLN-PZQ or market PZQ. Mice were sacrificed 14 days after treatment. Data are presented as the means \pm SEM. $n=6-8$ mice per group. ${ }^{\dagger}$ Significant difference vs $M-P Z Q$ at $P<0.05$. Abbreviations: $S L N-P Z Q$, solid lipid nanoparticle praziquantel; $\mathrm{M}-\mathrm{PZQ}$, market praziquantel

in the SLN delivery system was recorded in addition to higher efficacy in mice infected with $S$. mansoni and treated with this formulation. Parasitological findings revealed an increase in the percentage of worm reduction by 1.67-, 1.30- and 1.06-fold in infected mice treated with SLN-PZQ at doses of 62.5, 125 and $250 \mathrm{mg} / \mathrm{kg}$, respectively. Moreover, the $\mathrm{ED}_{95}$ was reduced to 176.89 $\mathrm{mg} / \mathrm{kg}$ for SLN-PZQ vs $936.13 \mathrm{mg} / \mathrm{kg}$ for M-PZQ. This enhanced efficacy is a result of the higher drug concentration in serum and decreased elimination as well as the prolonged time in the circulation. The antischistosomal effect of PZQ is associated with the absolute height of the maximal plasma concentration as well as the length of exposure to the drug [57]. Previous studies on nanoclay formulation of PZQ revealed enhanced bioavailability and higher efficacy in S. mansoni-infected mice, with a significant reduction in the dose by almost three times the conventional PZQ dose to achieve 50\% killing of $S$. mansoni worms [18]. Moreover, compared to conventional PZQ, the polymeric formulation of PZQ in solid dispersion reduced the $\mathrm{ED}_{50}$ by twofold [17].

Compared to M-PZQ, SLN-PZQ exhibited a stronger effect on the more troublesome female worms that was more evident at the lower dose levels (Table 3). This finding is in agreement with previous studies that showed superior activity of liposomal-PZQ and PZQ-solid dispersion against female worms [58-60] and the general preferential efficacy of PZQ against female adult worms [61]. In schistosomiasis, tolerance varies among Schistosoma species and varies among male and female worms. Male worms have more tolerance for PZQ activity [29, $62,63]$.

Compared to untreated control and equivalent doses of M-PZQ, SLN-PZQ at doses of 250, 500 and $1000 \mathrm{mg} /$ $\mathrm{kg}$ interrupted worm oviposition capacity, which was reflected as a significant reduction in both the hepatic and intestinal tissue egg load. The lower reduction in the hepatic tissue egg load with certain doses could be related to the higher density of eggs in hepatic tissues compared to intestinal tissue. The tendency of oviposition in the liver tissues after ceasing in the intestinal tissues was recorded upon treatment of $S$. mansoni-infected mice with subcurative doses of PZQ [61]. In the present study, the reduction in tissue egg load in mice treated with SLNPZQ coupled with complete disappearance of immature eggs, marked reduction in mature eggs and increase in dead eggs was recorded. The complete absence of total immature eggs in the oogram pattern is considered a significant indication of drug efficacy [64] and was especially evident in this work at the lowest doses tested (62.5 $\mathrm{mg} / \mathrm{kg}$ ). M-PZQ showed a similar effect against immature eggs only when the dose was quadrupled to $250 \mathrm{mg} /$ $\mathrm{kg}$. Previous empirical evidence showed that the recommended therapeutic dose of M-PZQ is not effective against immature eggs [65] and that repeating the dose nine days after the initial treatment would insult immature eggs [66].

SLN has superior advantages over conventional nanoformulations in terms of drug targeting, drug release modulation, long-shelf stability, low toxicity, better bioavailability and compatibility with several routes of administration [21, 22]. Several studies revealed an enhanced safety profile for lipid-carrier nanoformulations [23]. Moreover, PZQ showed an enhanced safety profile when incorporated in nanostructured lipid carriers [67], but liposomes and lipid emulsions as drug delivery systems revealed major drawbacks of drug leakage, hydrolysis, possible particle growth and instability during storage [22]. PZQ in nanoclay revealed significantly higher bioavailability and efficacy were recorded; nonetheless, there have been significant changes in haematological analysis and alterations in the cellular electrolyte balance in normal rats following the administration of large doses of montmorillonite clay [68-70]. Although the safety of SLN-PZQ was not tested in the present work, the 
mouse mortality rate has always been considered a safety indicator.

\section{Conclusions}

SLN potentiated the antischistosomal effect of PZQ where it contributed to a remarkably extended drug release as a result of the protection of the encapsulated drug from enzymatic degradation. Compared to administration of the conventional drug, oral administration of this SLN-PZQ showed significant enhancement of bioavailability and efficacy with a safer profile despite the longer residence in the systemic circulation. Further research involving safety is planned for future studies.

\section{Abbreviations}

PZQ: praziquantel; SLN: solid lipid nanoparticle; PDI: polydispersity index; EE: entrapment efficiency; ZP: zeta potential.

\section{Acknowledgements}

Not applicable.

\section{Authors' contributions}

SB, SS, NME and SW conceived and designed the study. AR, NME, GE and SW were responsible for the experiments. AR, MYA and GE analysed the data. AR, NME, SS and SB prepared the manuscript. All authors read and approved the final manuscript.

\section{Funding}

Not applicable.

\section{Availability of data and materials}

The data supporting the conclusions of this article are provided within the article.

\section{Ethics approval and consent to participate}

Ethics approval was granted by the Institutional Review Board of Theodor Bilharz Research Institute as well as the Research Ethics Committee for Experimental and Clinical Studies at Faculty of Pharmacy, Cairo University (Permit Number: PO.3.4.3, 2014).

\section{Consent for publication}

Not applicable.

\section{Competing interests}

The authors declare that they have no competing interests.

\section{Author details}

${ }^{1}$ Research Department, Academy of Scientific Research and Technology, Cairo, Egypt. ${ }^{2}$ Pharmacology Department, Theodor Bilharz Research Institute, Imbaba, Giza, Egypt. ${ }^{3}$ Parasitology Department, Theodor Bilharz Research Institute, Imbaba, Giza, Egypt. ${ }^{4}$ Pharmaceutical Technology Department, National Research Center, Giza, Egypt. ${ }^{5}$ Department of Pharmacology \& Toxicology, Faculty of Pharmacy, Cairo University, Giza, Egypt. ${ }^{6}$ School of Pharmacy, Newgiza University, Giza, Egypt.

Received: 29 January 2019 Accepted: 12 June 2019

Published online: 17 June 2019

\section{References}

1. McManus DP, Dunne DW, Sacko M, Utzinger J, Vennervald BJ, Zhou X-N. Schistosomiasis. Nat Rev Dis Primers. 2018;4:13.
2. Wang H, Naghavi M, Allen C, Barber RM, Bhutta ZA, Carter A, et al. Global, regional, and national life expectancy, all-cause mortality, and cause-specific mortality for 249 causes of death, 1980-2015: a systematic analysis for the global burden of disease study 2015. Lancet. 2016;388:1459-544.

3. Cioli D, Pica-Mattoccia L, Basso A, Guidi A. Schistosomiasis control: praziquantel forever? Mol Biochem Parasitol. 2014;195:23-9.

4. William S, Botros S, Ismail M, Farghally A, Day TA, Bennett JL. Praziquantel-induced tegumental damage in vitro is diminished in schistosomes derived from praziquantel-resistant infections. Parasitology. 2001;122:63-6.

5. Cioli D, Botros SS, Wheatcroft-Francklow K, Mbaye A, Southgate V, Tchuente LA, et al. Determination of ED50 values for praziquantel in praziquantel-resistant and-susceptible Schistosoma mansoni isolates. Int J Parasitol. 2004;34:979-87.

6. Hotez PJ, Fenwick A. Schistosomiasis in Africa: an emerging tragedy in our new global health decade. PLoS Negl Trop Dis. 2009;3:e485.

7. Hotez PJ, Pecoul B. "Manifesto" for advancing the control and elimination of neglected tropical diseases. PLoS Negl Trop Dis. 2010;4:e718.

8. Panic G, Keiser J. Acting beyond 2020: better characterization of praziquantel and promising antischistosomal leads. Curr Opin Pharmacol. 2018;42:27-33.

9. Zwang J, Olliaro PL. Clinical efficacy and tolerability of praziquantel for intestinal and urinary schistosomiasis-a meta-analysis of comparative and non-comparative clinical trials. PLoS Negl Trop Dis. 2014;8:e3286.

10. Fallon PG, Tao LF, Ismail MM, Bennett JL. Schistosome resistance to praziquantel: fact or artifact? Parasitol Today. 1996;12:316-20.

11. Fallon PG. Schistosome resistance to praziquantel. Drug Resist Update. 1998;1:236-41.

12. Bruce JI, Dias LC, Liang YS, Coles GC. Drug resistance in schistosomiasis: a review. Mem Inst Oswaldo Cruz. 1987;82:143-50.

13. Woelfle M, Seerden JP, de Gooijer J, Pouwer K, Olliaro P, Todd MH. Resolution of praziquantel. PLoS Negl Trop Dis. 2011;5:e1260.

14. Keiser J, Silue KD, Adiossan LK, N'Guessan NA, Monsan N, Utzinger J, et al. Praziquantel, mefloquine-praziquantel, and mefloquine-artesunate-praziquantel against Schistosoma haematobium: a randomized, exploratory, open-label trial. PLoS Negl Trop Dis. 2014;8:e2975.

15. Utzinger J, N'Goran EK, N'Dri A, Lengeler C, Tanner M. Efficacy of praziquantel against Schistosoma mansoni with particular consideration for intensity of infection. Trop Med Int Health. 2000;5:771-8.

16. Raso G, N'Goran EK, Toty A, Luginbühl A, Adjoua CA, Tian-Bi NT, et al. Efficacy and side effects of praziquantel against Schistosoma mansoni in a community of western Côte d'Ivoire. Trans R Soc Trop Med Hyg. 2004;98:18-27

17. El-Lakkany N, El-Din SHS, Heikal L. Bioavailability and in vivo efficacy of a praziquantel-polyvinylpyrrolidone solid dispersion in Schistosoma mansoni-infected mice. Eur J Drug Metab Pharmacokinet. 2012;37:289-99.

18. El-Feky GS, Mohamed WS, Nasr HE, El-Lakkany NM, Seifel-Din SH, Botros SS. Praziquantel in a clay nanoformulation shows more bioavailability and higher efficacy against murine Schistosoma mansoni infection. Antimicrob Agents Chemother. 2015;59:3501-8.

19. Malhado M, Pinto DP, Silva AC, Silveira GP, Pereira HM, Santos JG Jr, et al. Preclinical pharmacokinetic evaluation of praziquantel loaded in poly (methyl methacrylate) nanoparticle using a HPLC-MS/MS. J Pharm Biomed Anal. 2016;117:405-12.

20. Silva LD, Arrúa EC, Pereira DA, Fraga CM, Costa TLD, Hemphill A, et al. Elucidating the influence of praziquantel nanosuspensions on the in vivo metabolism of Taenia crassiceps cysticerci. Acta Trop. 2016;161:100-5.

21. Geszke-Moritz M, Moritz M. Solid lipid nanoparticles as attractive drug vehicles: composition, properties and therapeutic strategies. Mater Sci Eng C. 2016;68:982-94.

22. Tomiotto-Pellissier F, Miranda-Sapla MM, Machado LF, Bortoleti BTDS, Sahd CS, Chagas AF, et al. Nanotechnology as a potential therapeutic alternative for schistosomiasis. Acta Trop. 2017;174:64-71.

23. Doktorovová S, Kovačević AB, Garcia ML, Souto EB. Preclinical safety of solid lipid nanoparticles and nanostructured lipid carriers: current evidence from in vitro and in vivo evaluation. Eur J Pharm Biopharm. 2016;108:235-52. 
24. Bhandari R, Indu PK. A method to prepare solid lipid nanoparticles with improved entrapment efficiency of hydrophilic drugs. Curr Nanosci. 2013:9:211-20.

25. Kheradmandnia S, Vasheghani-Farahani E, Nosrati M, Atyabi F. Preparation and characterization of ketoprofen-loaded solid lipid nanoparticles made from beeswax and carnauba wax. Nanomedicine. 2010;6:753-9.

26. Marín RRR, Babick F, Hillemann L. Zeta potential measurements for non-spherical colloidal particles - practical issues of characterisation of interfacial properties of nanoparticles. Colloids Surf A Physicochem Eng Asp. 2017;532:516-21.

27. Xiao SH, Catto BA, Webster LT Jr. Quantitative determination of praziquantel in serum by high-performance liquid chromatography. J Chromatogr. 1983:275:127-32.

28. Gibaldi M, Perrier D. Pharmacokinetics. 2nd ed. New York: Marcel Dekker Inc; 1982

29. Liang Y, Bruce J, Boyd D. Laboratory cultivation of schistosome vector snails and maintenance of schistosome life cycles. Proc First Sino-Am Symp. 1987;1:34-48.

30. Duvall $\mathrm{RH}$, DeWitt WB. An improved perfusion technique for recovering adult schistosomes from laboratory animals. Am J Trop Med Hyg. 1967;16:483-6.

31. Kamel IA, Cheever AW, Elwi AM, Mosimann JE, Danner R. Schistosomamansoni and S-Haematobium infections in Egypt. I. Evaluation of techniques for recovery of worms and eggs at necropsy. Am J Trop Med Hyg. 1977;26:696-701.

32. Pellegrino J, Cunha AS, Faria J, Oliveira CA. New approach to screening of drugs in experimental Schistosomiasis mansoni in mice. Am J Trop Med Hyg. 1962;11:201-15.

33. Ruktanonchai U, Bejrapha P, Sakulkhu U, Opanasopit P, Bunyapraphatsara $\mathrm{N}$, Junyaprasert $\mathrm{V}$, et al. Physicochemical characteristics, cytotoxicity, and antioxidant activity of three lipid nanoparticulate formulations of alphalipoic acid. AAPS PharmSciTech. 2009;10:227-34.

34. Kalepu S, Nekkanti V. Insoluble drug delivery strategies: review of recent advances and business prospects. Acta Pharm Sin B. 2015;5:442-53.

35. Weng HB, Chen HX, Wang MW. Innovation in neglected tropical disease drug discovery and development. Infect Dis Poverty. 2018;7:67.

36. Morris ZS, Wooding S, Grant J. The answer is 17 years, what is the question: understanding time lags in translational research. J R Soc Med. 2011;104:510-20

37. Day TA, Kimber MJ. Praziquantel interaction with mammalian targets in the spotlight. Trends Parasitol. 2018;34:263-5.

38. Kasinathan RS, Morgan WM, Greenberg RM. Schistosoma mansoni express higher levels of multidrug resistance-associated protein 1 (SmMRP1) in juvenile worms and in response to praziquantel. Mol Biochem Parasitol. 2010;173:25-31.

39. Chaiworaporn R, Maneerat Y, Rojekittikhun W, Ramasoota P, Janecharut T, Matsuda $\mathrm{H}$, et al. Therapeutic effect of subcurative dose praziquantel on Schistosoma mansoni infected mice and resistance to challenge infection after treatment. Southeast Asian J Trop Med Public Health. 2005;36:846-52.

40. Muller RH, Mader K, Gohla S. Solid lipid nanoparticles (SLN) for controlled drug delivery - a review of the state of the art. Eur J Pharm Biopharm. 2000;50:161-77.

41. Yang L, Geng Y, Li H, Zhang Y, You J, Chang Y. Enhancement the oral bioavailability of praziquantel by incorporation into solid lipid nanoparticles. Pharmazie. 2009;64:86-9.

42. de Souza AL, Andreani T, de Oliveira RN, Kiill CP, dos Santos FK, Allegretti $\mathrm{SM}$, et al. In vitro evaluation of permeation, toxicity and effect of praziqu antel-loaded solid lipid nanoparticles against Schistosoma mansoni as a strategy to improve efficacy of the schistosomiasis treatment. Int J Pharm. 2014:463:31-7.

43. Uner M, Yener G. Importance of solid lipid nanoparticles (SLN) in various administration routes and future perspectives. Int J Nanomed. 2007;2:289-300

44. Doktorovova S, Shegokar R, Souto EB. Role of excipients in formulation development and biocompatibility of lipid nanoparticles (SLNs/NLCs). In: Ficai D, Grumezescu AM, editors. Nanostructures for novel therapy. Amsterdam: Elsevier; 2017. p. 811-43.

45. Bentley AO, Rawlins EA. Bentley's textbook of pharmaceutics. London, UK: Baillï̈re Tindall; 1977.
46. Danaei M, Dehghankhold M, Ataei S, Davarani FH, Javanmard R, Dokhani A, et al. Impact of particle size and polydispersity index on the clinical applications of lipidic nanocarrier systems. Pharmaceutics. 2018;10:E57.

47. Andrews P, Dycka J, Frank G. Effect of praziquantel on clinical-chemical parameters in healthy and schistosome-infected mice. Ann Trop Med Parasitol. 1980;74:167-77.

48. Botros SS, El-Din SHS, El-Lakkany NM, Sabra ANA, Ebeid FA. Drugmetabolizing enzymes and praziquantel bioavailability in mice harboring Schistosoma mansoni isolates of different drug susceptibilities. J Parasitol. 2006:92:1344-9.

49. Mandour ME, El Turabi H, Homeida MM, El Sadig T, Ali HM, Bennett JL, et al. Pharmacokinetics of praziquantel in healthy volunteers and patients with schistosomiasis. Trans R Soc Trop Med Hyg. 1990;84:389-93.

50. El Guiniady MA, El Touny MA, Abdel-Bary MA, Abdel-Fatah SA, Metwally A Clinical and pharmacokinetic study of praziquantel in Egyptian schistosomiasis patients with and without liver cell failure. Am J Trop Med Hyg. 1994;51:809-18.

51. Badawi AF, Mostafa MH. Possible mechanisms of alteration in the capacities of carcinogen metabolizing enzymes during schistosomiasis and their role in bladder cancer induction. J Int Med Res. 1993:21:281-305.

52. Brant PC, Prata A. Altered drug metabolism in hepatosplenic schistosomiasis. Rev Inst Med Trop Sao Paulo. 1979;21:254-9.

53. Tekwanl BL, Shukla OP, Ghatak S. Altered drug metabolism in parasitic diseases. Parasitol Today. 1988;4:4-10.

54. Xie S, Pan B, Shi B, Zhang Z, Zhang X, Wang M, et al. Solid lipid nanoparticle suspension enhanced the therapeutic efficacy of praziquantel against tapeworm. Int J Nanomed. 2011;6:2367-74.

55. Maisel K, Ensign L, Reddy M, Cone R, Hanes J. Effect of surface chemistry on nanoparticle interaction with gastrointestinal mucus and distribution in the gastrointestinal tract following oral and rectal administration in the mouse. J Control Release. 2015;197:48-57.

56. Ganesan P, Narayanasamy D. Lipid nanoparticles: different preparation techniques, characterization, hurdles, and strategies for the production of solid lipid nanoparticles and nanostructured lipid carriers for oral drug delivery. Sustain Chem Pharm. 2017:6:37-56

57. Gonnert R, Andrews P. Praziquantel, a new broad-spectrum antischistosomal agent. Z Parasitenkd. 1977;52:129-50.

58. Frezza TF, Gremiao MP, Zanotti-Magalhaes EM, Magalhaes LA, de Souza AL, Allegretti SM. Liposomal-praziquantel: efficacy against Schistosoma mansoni in a preclinical assay. Acta Trop. 2013:128:70-5.

59. Frezza TF, de Souza ALR, Prado CCR, de Oliveira CNF, Gremião MPD, Giorgio S, et al. Effectiveness of hyperbaric oxygen for experimental treatment of Schistosomiasis mansoni using praziquantel-free and encapsulated into liposomes: assay in adult worms and oviposition. Acta Trop. 2015;150:182-9.

60. Marques CSF, Rezende P, Andrade LN, Mendes TMF, Allegretti SM, Bani C, et al. Solid dispersion of praziquantel enhanced solubility and improve the efficacy of the schistosomiasis treatment. J Drug Deliv Sci Technol. 2018:45:124-34.

61. Delgado VS, Suarez DP, Cesari IM, Incani RN. Experimental chemotherapy of Schistosoma mansoni with praziquantel and oxamniquine: differential effect of single or combined formulations of drugs on various strains and on both sexes of the parasite. Parasitol Res. 1992;78:648-54.

62. James CE, Hudson AL, Davey MW. An update on P-glycoprotein and drug resistance in Schistosoma mansoni. Trends Parasitol. 2009:25:538-9.

63. Pinto-Almeida A, Mendes T, Armada A, Belo S, Carrilho E, Viveiros M, et al. The role of efflux pumps in Schistosoma mansoni praziquantel resistant phenotype. PLoS ONE. 2015;10:e0140147.

64. Pellegrino J, Faria J. The oogram method for the screening of drugs in Schistosomiasis mansoni. Am J Trop Med Hyg. 1965;14:363-9.

65. Cheever AW, Anderson LA. Rate of destruction of Schistosoma mansoni eggs in the tissues of mice. Am J Trop Med Hyg. 1971;20:62-8.

66. Richards F Jr, Sullivan J, Ruiz-Tiben E, Eberhard M, Bishop H. Effect of praziquantel on the eggs of Schistosoma mansoni, with a note on the implications for managing central nervous system schistosomiasis. Ann Trop Med Parasitol. 1989:83:465-72.

67. Kolenyak-Santos F, Garnero C, De Oliveira RN, De Souza ALR, Chorilli M, Allegretti SM, et al. Nanostructured lipid carriers as a strategy to improve the in vitro schistosomiasis activity of praziquantel. J Nanosci Nanotechnol. 2015;15:761-72. 
68. Wiles MC, Huebner HJ, Afriyie-Gyawu E, Taylor RJ, Bratton GR, Phillips TD. Toxicological evaluation and metal bioavailability in pregnant rats following exposure to clay minerals in the diet. J Toxicol Environ Health A. 2004;67:863-74.

69. Lee Y-H, Tzong-Fu K, Bor-Yann C, Yi-Kai F, Yu-Ren W, Wu-Ching L, et al. Toxicity assessment of montmorillonite as a drug carrier for pharmaceutical applications: yeast and rats model. Biomed Eng Appl Basis Commun. 2005;17:72-8.
70. Jayrajsinh S, Shankar G, Agrawal YK, Bakre L. Montmorillonite nanoclay as a multifaceted drug-delivery carrier: a review. J Drug Deliv Sci Technol. 2017:39:200-9.

\section{Publisher's Note}

Springer Nature remains neutral with regard to jurisdictional claims in published maps and institutional affiliations.
Ready to submit your research? Choose BMC and benefit from:

- fast, convenient online submission

- thorough peer review by experienced researchers in your field

- rapid publication on acceptance

- support for research data, including large and complex data types

- gold Open Access which fosters wider collaboration and increased citations

- maximum visibility for your research: over $100 \mathrm{M}$ website views per year

At BMC, research is always in progress.

Learn more biomedcentral.com/submissions 